\title{
Integrated Product Development in the Classroom
}

\author{
Mel Mendelson, Cal Caswell \\ Loyola Marymount University
}

\begin{abstract}
A course entitled, "New Product Design and Development" was introduced to meet the needs of industry and to address reform in engineering education. It was modeled after a similar one taught at MIT; however, it had distinctly different features. The course used multi-discipinary teams and product planning to create commercial products. Our course emphasized team building, marketing, design, prototyping, and the business aspects of launching a new product on the market.
\end{abstract}

\section{Introduction}

Integrated product development (IPD) is also referred to as concurrent engineering. It is defined as the simultaneous integration of the design, engineering, manufacturing, business and management activities that are necessary for developing a product from its conception to marketlaunch and maintaining the product throughout its life cycle [1]. IPD is important because it represents the building block of the future for U.S. manufacturing, and it is the key to survival for aerospace/defense [2]. Two-thirds of the U.S. companies use integrated product teams [3].

Over the last two years, Loyola Marymount University (LMU) has conducted surveys and held focus groups with key executives in manufacturing to identify industry's needs in Southern California [4]. Over thirty manufacturing companies, state and federal agencies responded that their greatest need was educating engineers in integrated product development. Both small and large size companies need to have their employees educated in the skills of IPD for jobs of the future [2].

The Committee on Science, Engineering and Public Policy has recommended that a broader, more flexible, cross-functional education be implemented for graduate scientists and engineers [5]. However, very few U.S. universities offer cross-functional courses that address integrated product development [6]. The major difficulty has been the faculty's lack of motivation, ability and multi-disciplinary experience in teaching integrated courses [7]. MIT was one of the few universities that offered such a course (Product Design and Development), which was used as our model.

Our course was structured to meet industry's needs and to promote collaborative learning. The course was planned over a one year period and addressed curriculum reform in engineering education [7]. The purpose of this paper is to describe LMU's course ("New Product Design and Development"), its requirements and expectations, the product and team selection, the differences between our course and MIT's course, and our lessons learned. 


\section{Course Description}

In the spring of 1996 a new course entitled, "New Product Design and Development" was offered, which was co-taught between the LMU's Colleges of Science and Engineering and Business Administration. It also included the Southern California Institute of Architecture (SCIArc). This was a one semester course, which lasted 15 weeks. It was a 3 semester hour course that met once a week for 3 hours. Currently this course has been taught three times. The course prerequisites were advanced undergraduate status or graduate status in engineering, design or business.

The goal of the course was to use the concurrent engineering approach and multi-disciplinary planning for creating new products. Cross-functional teams of engineering, business and architecture students (at the outset) worked together to define commercial market-driven products, to identify the customer needs, to develop engineering designs, to construct prototypes, and to perform a business analysis on the products. It focused on open-ended, creative problem solving. The textbook for our course was written by MIT professors, who use it in their course [8].

The course included the following topics: planning and integrating multi-disciplinary activities; technology/market assessment; total quality management (product leadership, strategic planning, team building and group dynamics, competitive benchmarking, customer-focus and continuous process improvement), market research; customer needs identification; product specifications; introduction to quality function deployment (QFD); design generation/selection; systems level architecture; fabrication of prototypes; design for manufacturing and assembly (DFMA); designing for high quality, low cost and fast time-to-market; estimating manufacturing costs; product economics (net present value, break-even analysis and payback period); and project reviews.

The concurrent engineering approach was used in the early stages of the planning cycle before the final design was determined [1]. The activities that were utilized in the process are shown in Figure 1. These activities were conducted through team assignments. The course grades were weighted as follows: assignments (20\%), team design reviews (30\%), design and constructing prototypes (30\%), and final team report (20\%). The grading criteria were based upon the product creativity, thoroughness of the work, meeting the project goals, and completing assignments on time. Initially, no exams were given in the course. 


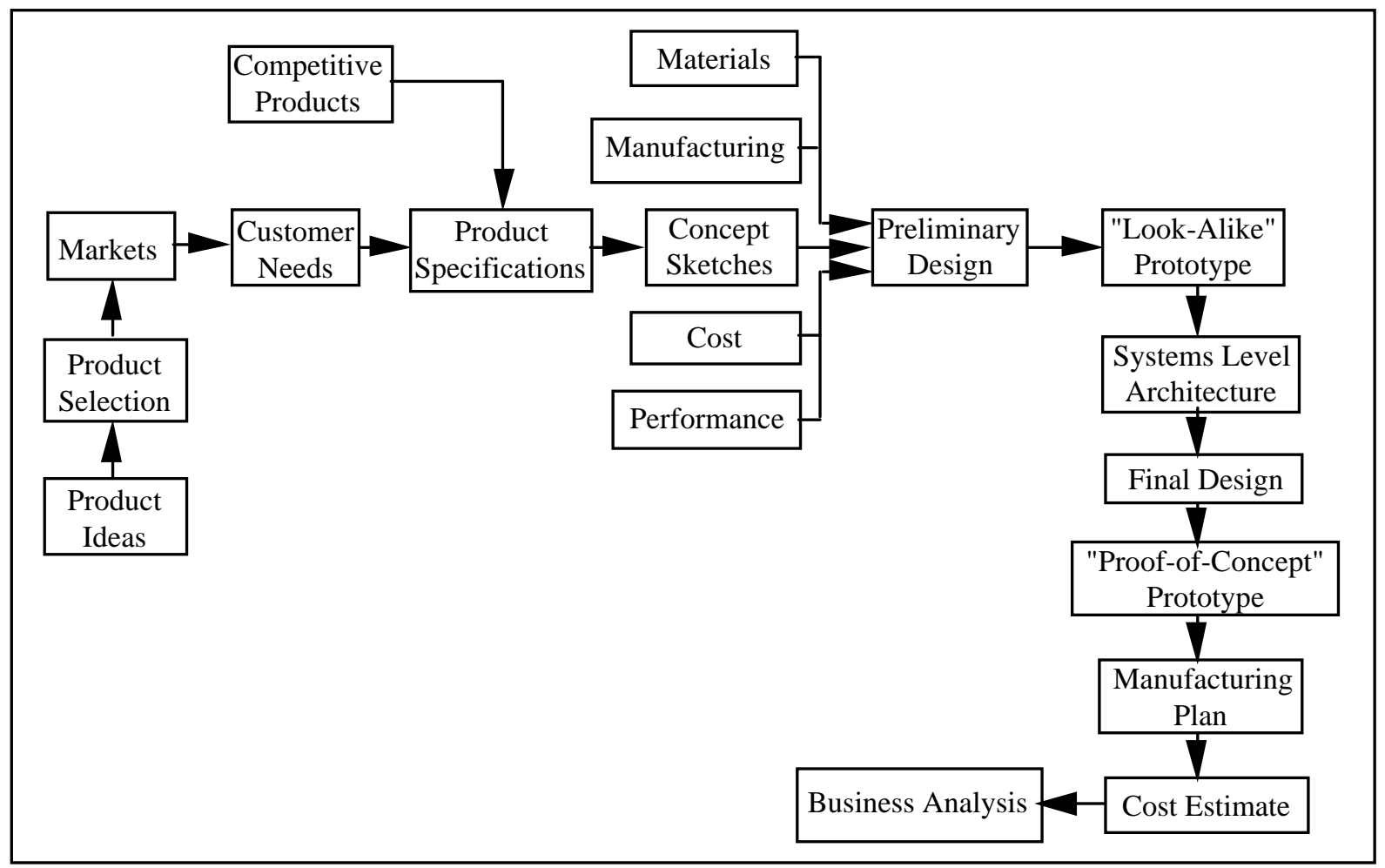

Figure 1. Product Planning and Development Process

The 3 hour weekly class schedule was typically divided into 1.5 hours of lecture and 1.5 hours for the team projects. The teams were expected to meet outside of class to complete their assignments. Due to reduced lecture time, the instructors had to rely on the students reading the text. The instructors lectured on the key points in each chapter; and then provided project assignments to the teams, which emphasized the material in the chapters that related to their products. The instructors also utilized the class time to advise the teams on their specific products [9].

The course was co-taught by a full-time instructor from mechanical engineering, a part-time instructor from business, and initially a part-time instructor in industrial design from SCI-Arc. The course was divided up into topics, and each instructor was responsible for that topic in the textbook during the class. In situations where the topics overlapped several disciplines, the instructors would discuss the topics from different perspectives. In many cases, the instructors had different perceptions of the subject material. However, the definitions in the textbook were used as the guide throughout the course.

Consultants had participated in the course as guest lecturers and/or advisors to the projects. A patent attorney with an engineering background discussed patent law and how to file a patent. An investment banker discussed capital funding for new products in start-up ventures. During the project reviews, outside people from industrial design, marketing, project management and university faculty/staff were present to ask questions and to provide assistance on the projects. Although industry did not provide technical support, the Northrop Grumman Corporation financed the team projects. 


\section{Requirements and Expectations}

The selected products were required to be commercially manufactured goods, not services that have a defined market and customers. The products had to be simple (less than 10 parts) and not contain proprietary, classified or sensitive information. In addition, the products were not intended to directly compete with each other; each team was expected to assist the other teams with possible solutions to their problems during the presentations. Each team was expected to keep track of the number of hours spent working on the planning, design and development. This time was used to estimate the cost for concept development. Finally, each team was allocated a budget of $\$ 500$ for materials and supplies in the construction of their prototypes.

The teams had to deliver four oral presentations: (1) proposal of the product concepts, (2) project plan and schedule, (3) preliminary design review (PDR) and (4) critical design review (CDR). At the beginning of the course, each student had to deliver a proposal with the purpose of persuading the class that his/her product idea was the most interesting concept. The second oral presentation involved identifying their team goals and activities, dividing up the activities among the team members, and putting a time line on the plan. The third presentation was the PDR, which occurred at midterm and covered the activities from product idea to "look-alike" prototype (see Figure 1). The fourth presentation was the CDR, which occurred at the end of the course and comprised the activities from the system architecture to the business analysis (see Figure 1). It represented a confirmation of product design and development before resources were committed. Before the CDR, a reception was held for the teams to celebrate the completion of their projects, and food and drinks were served.

After the presentations were completed, final reports were required from the teams. The reports included all of the items in the design reviews: the product idea, mission statement, customer needs and product specifications, detail and assembly drawings, "proof-of-concept" prototype (exhibiting actual size, shape and functionality), manufacturing plan (materials/processing, process flow diagrams, schedule, manpower), cost estimate (for design, manufacturing and distributing the product on the market); estimated capital investment for operating expenses; and a business analysis (consisting of marketing strategy, competitive benchmarking, number of units, unit price, break-even analysis and payback period).

\section{Product and Team Selection}

So far, the product ideas have been conceived by the students, not by the faculty or industry. In the first class, examples of previous student-conceived products were presented by the instructors. The students were given references to generate creative ideas for products; they were encouraged to speak with marketing people and to search the internet for ideas. They were expected to be creative and to keep the product concept simple. It was important for the students to choose their ideas from products that did not require new technologies to develop. Available ("off-the-shelf") technology was mandatory. Products that were portable, collapsible, saved space or provided flexibility were recommended. Examples of the products that originated from our course have included: release binding for snowboards, ergonomic devices for disabled people, portable safety signs for automobiles, portable rollerblade covers for skaters, portable cup holder for drinks in automobiles, snap-on hinges for eyeglasses and mini-mop for cleaning.

In the second class, the students presented their proposals on the product concepts. Afterwards, the students voted for their favorite product concepts in class. The multi-voting method was used to achieve consensus on the product concepts ${ }^{[10]}$. Then the students were grouped into 
teams around their interest in the products. Each team had 4 to 5 students that contained engineering, business and architecture students.

The projects were organized into self-directed teams for planning and developing the products. The teams had to select managers for the major activities (see Figure 1). The managers were responsible for completing the tasks of that activity on schedule and meeting the goals of the course. The other team members were expected to assist the managers in the completion of these activities. For conducting efficient team meetings, each student was required to take on a role, i.e., team captain, secretary, treasurer, time keeper and interrupter [11].

\section{Course Differences}

MIT's product development course was a 12 semester hour course, and it was offered twice a week for 15 weeks. The students were expected to spend at least 12 hours/week, and in many cases they spent 15-20 hours/week on the course [12,13]. On the other hand, LMU's course was 3 semester hours. Most of our students spent about 10 hours/week outside of class on their projects.

In LMU's course, the grading included final written reports on the technology/business analysis of the products ( $20 \%$ of the course grade). MIT did not require any reports at the end of the course, only a final presentation. In both cases, the institutions did not require exams in the course. LMU's course assignments focused on the team projects, whereas MIT had homework problems, case studies and extra reading material in addition to the team projects. LMU placed $20 \%$ of grade on the critical design review (CDR), where MIT placed heavier emphasis (34\%) on their final presentation [12].

The process of selecting products and organizing the teams was slightly different. At LMU, the products and teams were selected in class after the proposals were presented and discussed. The students voted on their product preference; then they chose the multi-disciplinary teams around their peers' product interest. This allowed time for the students to negotiate their preferences. At MIT, the instructors assigned the teams based upon ballots that the students submitted on their product preferences [12].

The construction of prototypes was different in LMU's course, due to the limited time and resources of the students. The construction of alpha prototypes [8] was usually too ambitious for the teams to complete. A more realistic objective was having the students build a "proof-ofconcept" prototype that consisted of the product size, shape and functionality but did not include the bill-of-materials [11]. The prototypes were usually fabricated by conventional machining or by casting/machining the parts. At MIT, the students were required to build alpha prototypes.

The most important guideline for effective product performance was having the team in one location [10]. In LMU's course, all of the engineering, business and architecture students were enrolled in the same course, and it was taught in one location. Due to close proximity of the LMU and SCI-Arc campuses (about 1 mile apart), classes were rotated between LMU and SCIArc. The students liked this variety. As previously mentioned, about $50 \%$ of the class time was devoted to the team projects due to the difficulty of the students meeting as a team during the week. Because the students were spread out over a 40 mile radius of the LMU campus, they could only meet together on weekends. During the week, they communicated by telephone, FAX and e-mail. 
In MIT's course, all of the students were not enrolled in same course at one location [13]. The engineering and business students were co-located on campus in Cambridge. The design students were located at the Rhode Island School of Design, and they would attend about onehalf of the classes at MIT. In some semesters, the design students would not attend any classes $[13]$.

At LMU, course continuity was maintained by having the same instructors teach the course. The part-time architecture instructor only co-taught the course once. In this way the course format and expectations remained consistent. In MIT's course, every year over the last 8 years the faculty team and course format have changed [13], which has provided less continuity. At LMU, only one of the instructors was full-time faculty with a tenure-track position; the other instructors were part-time. At MIT, only full-time, tenured faculty taught their course.

\section{Lessons Learned}

The first time LMU's course was taught, our team of instructors believed that there was strength in diversity and unity of purpose. As the course evolved, it became apparent that the values and methodologies were different between the architecture instructor and the engineering and business instructors. The architecture instructor treated the course as a "capstone" project course, where the instructor's job was to foster creativity and to advise the students on their projects. The instructor did not believe in preparing lectures, grading assignments and neglected the course assessment and the evaluation of learning, which have become a major concern in higher education. The engineering and business instructors provided lectures on the principles of the course, and graded the assignments and team projects.

The above differences in teaching methods created stress among the instructors, which was carried into the classroom and detected by the students. During the first half of the course, the instructors were in the "storming" phase [9]. Although this was normal, the experience was difficult for the students to accept as being constructive. At the conclusion of the course, the instructors had smoothed out the major difficulties and had progressed to the "norming" phase [9].

The second and third time the course was offered, it was co-taught by the engineering and business instructors. Many of the teaching methods and values were similar between these two disciplines. The classes had less diversity, but they also had less tension and higher student morale. The students were more relaxed and happier than those in the first course, which made learining a more enjoyable experience.

Our course illustrated the fact that team teaching takes a great deal of time in planning and coordination. Collaboration between the instructors was limited because the part-time instructors had other responsibilities. In order to coordinate the classes, the full-time instructor distributed a class plan by FAX or e-mail to the part-time instructors several days before the next class. The part-time instructors made comments or changes to the plan and returned it to the fulltime instructor before the class. Then the instructors would usually meet before class to discuss class plan. In this way a consistent, unified message was presented, and it minimized impromptu changes that gave mixed signals to the students. 
Due to the large volume of project work in the course, it was discovered that the students were not seriously reading the textbook. Hence, the students misinterpreted some of the principles of

the course. In spite of these difficulties, the collaborative team projects were successfully completed.

The following recommendations are made for improving the course. It is important for the instructors to agree up-front on the course expectations and to work together on developing the course strategy. Grading assignments and providing students with feedback on their projects should be a shared responsibility of the instructors. An exam should be given in future classes to encourage the students to carefully read the textbook. In order to have more time for faculty collaboration, it is suggested that full-time instructors teach the course. In addition, it would be desirable to have tenured faculty teach this course because cross-functional collaborative teaching is difficult to implement.

\section{Conclusions}

The goal of LMU's "New Product Design and Development" course was to design products, build prototypes, and analyze the marketing/business aspects of launching new commercial products. MIT's product design and development course was used as model for our integrated product teams. However, our course was distinctly different in terms of lower course credit (3 semester hours), different course expectations, different product and team selection process, having the project teams co-located, and having continuity in the teaching of the course.

In our course, commercial products were planned and developed by multi-disciplinary teams of engineering, business and architecture students. The team teaching format and having guest lecturers from industry simulated "real world" situations. The students selected their own products and teams, performed marketing/competitive analyses, identified the customer needs, developed the product specifications and final designs, selected the materials and processes, built prototypes, created manufacturing plans, estimated the development and manufacturing costs, and performed a break-even/payback analysis for their products. The teams were given a budget to construct their prototypes. Although team teaching was beneficial for diversity, it was very stressful. Early commitment to the course expectations and frequent communication of the instructors were necessary for a successful course.

\section{Acknowledgments}

The concurrent engineering concepts were partially supported by the National Science Foundation Grant \#DUE-991741 for improving the engineering curriculum. A special thanks is given to the Northrop Grumman Corporation for generously providing grants to finance the team projects. 


\section{References}

1. J. R. Hartley, Concurrent Engineering: Shortening Lead Times, Raising Quality and Lowering Costs, Productivity Press, Portland, OR, 1992.

2. "Integrated Product Development," Executive Seminar, California Polytechnic University, San Luis Obispo, CA, July 28, 1995.

3. "Teams Become Commonplace in U.S. Companies," Wall St. Journal, p.1, November 25, 1995.

4. M.I. Mendelson, Results from 2 surveys assessing industry's needs in Southern California; performed on Sept. 1994 and Oct. 1995.

5. P.A. Griffiths, "Breaking the Mold," ASEE Prism, pp. 27-31, November 1995.

6. P. Lawrence, Teaching Collaborative Product Development, Corporate Design Foundation, Boston, MA, (617)350-7097, 1994.

7. R.S. Blackburn (Univ. of North Carolina), "Interdisciplinary Product Development Education: Results of a Survey," Teaching Collaborative Product Development, Corporate Design Foundation Report, Boston, MA, (617)350-7097, p. 47, 1994.

8. K.T. Ulrich and S.D. Eppinger, Product Design and Development, McGraw-Hill, 1995.

9. D.R. Woods, Problem Based Learning: How to Gain the Most from PRL, Waterdown, Ontario, 1994.

10. P.R. Scholtes, The Team Handbook, Joiner Associates Inc., 1988.

11. Toastmasters Int'l, Communication and Leadership Program, Mission Veijo, CA, (714)858-8255, 1988.

12. K.T. Ulrich and S.D. Eppinger, Instructor's Manual to Accompany Product Design and Development, McGrawHill, 1995.

13. S.D. Eppinger (MIT Sloan School of Management), personal communication, November 1995 - present.

\section{MEL I. MENDELSON}

Received his B.S. (1964) from UC Berkeley, his M.S. (1966) and Ph.D. (1973) from Northwestern University all in materials science. He has worked 24 years in industry and has 11 years experience in teaching. He became director of the Engineering and Production Management graduate program and assoc. professor of ME at Loyola Marymount University in Los Angeles (1994). He is interested in manufacturing, concurrent engineering and failure analysis.

\section{CAL CASWELL}

Completed his B.A. (1968) and M.A. (1973) from Loyola Marymount University in business administration. He is currently a candidate to receive his Ed.D. in higher education from Nova University. He has 20 years of industrial experience in marketing and project management and has 15 years experience in teaching. Since 1993, he has been director/coordinator of the Workplace Learning Resource Center at El Camino College in Torrance, CA. 